\title{
Human Papillomavirus Infection and Awareness of Human Papillomavirus Vaccines among Various Ethnicities in Libya
}

\author{
Salma Korbag, Issa Korbag \\ Department of Chemistry, College of Arts and Science, University of Benghazi, Al Kufra, Libya
}

\section{Abstract}

Background: Human papillomavirus (HPV) plays a role in increasing the risk of cervical cancer and other cancers. This study aimed to explore the incidence of HPV infection among various ethnicities in Libya. Furthermore, awareness and knowledge of HPV vaccines in the community were explored.

Methods: A descriptive study was conducted to present HPV infection among cancer cases using the National Cancer Registry of Libya year 2011-2020, including gender, skin color, and ethnicity. Furthermore, awareness and knowledge of the HPV vaccines were assessed using questionnaires distributed through social media. Data were presented in percentage.

Results: In total, there were 33,526 (58.1\%) infected HPV-related cancers out of 57,620 cancer cases, of whom 25,296 (75.4\%) were women and 8,230 (24.6\%) were men. Based on cancer sites, the incidence of HPV-related cancers among whites was higher ( $>63 \%$ and more) than blacks except for anal cancer, of which blacks had a slightly higher incidence ( $54 \%$ in females and $57 \%$ in males). Based on ethnicity, native Libyans such as Tabu, Touareg, and Berbers had different cancer sites. Moreover, the knowledge and awareness about HPV and related cancers were very poor among the population in Libya.

Conclusions: Although HPV cancers represent a high percentage of cancer burdens among Libyans, awareness and knowledge on HPV and related cancer are lacking. Better education and provision of the HPV vaccines for future generations may eliminate and reduce HPV-related cancers.

Keywords: Anal cancer, cervical cancer, HPV, Libya, sexually transmitted disease

\section{Introduction}

Human papillomavirus (HPV) is a common sexually transmitted virus, infecting most women and men during their lives. Based on the cancer potential, viruses are classified into high risk and low risk. ${ }^{1,2}$ In many cases, infection with the HPV occurs without the appearance of any symptoms. However, HPV infection may develop in various types of cancer in some women and men, in accordance with the target organ. About $70 \%$ of HPV16 and HPV-18 are at high risk of causing cervical cancer (CC), in addition to a subset of genital anal cancer especially in the vagina, vulva, anus, penis, and pharyngeal cancers. ${ }^{3,4}$ Currently, there are three HPV vaccines available in the global market, that are highly effective against various HPV genotypes. ${ }^{5-9}$ The bivalent vaccine covers HPV-16 and HPV-18; whereas the quadrivalent vaccine covers also low-risk HPV-6 and HPV-11, next to the highrisk HPV-16 and HPV-18. Moreover, five other extra high-risk genotypes of the nonavalent vaccines have been added, including HPV-31, HPV-33, HPV-45, HPV-52, and HPV-58. The protection against HPV infection is about nine years and a minimum of twenty years for high antibody concentration levels. ${ }^{10}$

Many countries have started HPV vaccination programs, right after the introduction of HPV vaccines. For example, Mexico had adopted the first quadrivalent HPV vaccine in 2006. The World Health

Correspondence: Salma Korbag, Department of Chemistry, College of Arts and Science, University of Benghazi, Al Kufra, Libya, E-mail: salma.omar46@yahoo.com 


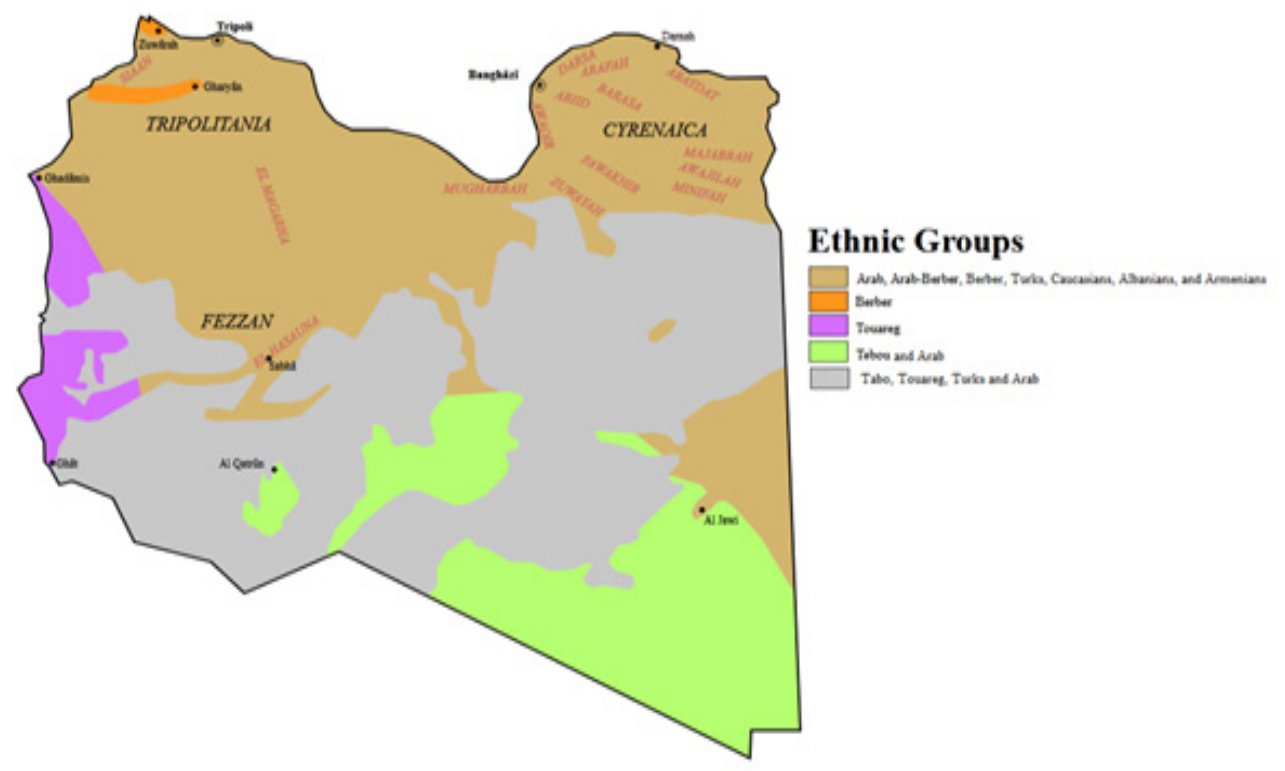

Figure Libyan Country and Dominant Ethnic Groups

Organization (WHO) had finally recommended routine vaccination against HPV in 2009. The actual effectiveness of HPV vaccines has become increasingly evident in countries with high vaccine absorption, especially in young women before exposure to HPV. ${ }^{11}$ At the population level, the effects of vaccination against HPV decrease the HPV prevalence, cellular abnormalities in the cervix, and genital warts (GWs).12,13 The Committee on Immunization Practices (CIP) recommends that the vaccine should be administered routinely to females and males aged between 11 and 12; however, a study in this age group is limited. ${ }^{14,15}$ This study aimed to determine the prevalence of HPV infected cases in developing various cancers in Libya in the past decade. Furthermore, knowledge of HPV vaccines in the community was explored, hoping to educate various ethnicities in Libya about different types of HPV infection in women and men, and awareness of vaccinations against HPV.

\section{Methods}

This descriptive study had used nationally representative data from the National Cancer Registry of Libya year 2011-2020, predominantly from the national hospital's medical records. The incidence of HPV infection-associated cancer was stratified by gender, skin color, and ethnicity. As for ethnicity, the African native people in Libya were Tabu, Touareg, and Berbers; the Asian was mostly Arabs; the European were Turks, Caucasians, Albanians, and Armenians as shown in Figure. Since this investigation used secondary data freely available in the public domain where there was no mentioning of the sample identity, ethical approval was unnecessary.

To assess HPV knowledge and vaccine in the community, Twitter and Facebook were used to recruit participants. A short validated questionnaire was distributed between 2019 and 2020 to explore the extent of citizens' education and knowledge of vaccines against papillomavirus. The data was anonymously gathered, therefore, ethical approval was not required. Data was further presented in percentage.

\section{Results}

The total subjects registered HPV infections in the National Registry from 2011 to 2020 were 57,620 , including $72.8 \%$ cancer in females and $27.2 \%$ in males. Furthermore, infected HPVrelated cancers was found in 33,526 (58.1\%) of whom $75.4 \%(n=25,296)$ were females and $24.6 \%(n=8,230)$ were males (Table 1$)$.

Although there was variation in the exact number of HPV-related cancers in Libya, data confirmed that HPV was associated with most cancers in the genital area, accounting for $60 \%$ and $52 \%$, respectively, among females and males. Of those HPV infection cases in women, 
Table 1 Incidence of Human Papillomavirus-related Cancers Based on Infected Organ Site, Stratified by Gender in Libya from 2011 to 2020

\begin{tabular}{|c|c|c|c|c|c|}
\hline Gender & Total All & Cancer Site & Cases (n) & $(\%)$ & $(\%)^{* * *}$ \\
\hline Female & $\begin{array}{l}\text {-All HPV-related cancers } \\
\text {-Other cancer } \\
\text { Total female }\end{array}$ & $\begin{array}{l}\text { Ovaries } \\
\text { Cervix } \\
\text { Anus } \\
\text { Vulva } \\
\text { Oropharynx } \\
\text { Vagina }\end{array}$ & $\begin{array}{c}25,296 \\
9,264 \\
8,786 \\
3,968 \\
1,697 \\
952 \\
629 \\
16,638 \\
41,934\end{array}$ & $\begin{array}{c}40^{*} \\
72.8^{* *}\end{array}$ & $\begin{array}{c}36 \\
35 \\
16 \\
7 \\
4 \\
2\end{array}$ \\
\hline Male & $\begin{array}{l}\text {-All HPV-related cancers } \\
\text {-Other cancer Total male }\end{array}$ & $\begin{array}{l}\text { Oropharynx } \\
\text { Anus } \\
\text { Penis } \\
\\
\text { TOTAL }\end{array}$ & $\begin{array}{c}8,230 \\
4,115 \\
2,971 \\
1,144 \\
7,456 \\
15,686 \\
57,620\end{array}$ & $\begin{array}{c}52^{*} \\
\\
\\
48^{*} \\
27.2^{* *} \\
100^{* *}\end{array}$ & $\begin{array}{l}50 \\
36 \\
14\end{array}$ \\
\hline
\end{tabular}

Note. *percentage in total females $(n=41,934)$ or males $(n=15,686) ; * *$ percentage of all HPV related cancers and other cancer $(n=57,620) ;{ }^{* * *}$ percentage in cancer site for all HPV related cancers in female $(n=25,296)$ or males $(n=8,230)$.

ovarian (36\%) and cervical cancer (CC; 35\%) alone represented predominantly of all HPVrelated cancers; whereas pharyngeal cancer accounted for $4 \%$. On the contrary, oropharynx cancer in men accounted for $50 \%$ of total HPVrelated cancer (Table 1).

HPV-related cancers affected ethnic groups to varying degrees. Generally, rates of HPV-associated cancers in whites (85\%) were higher than in blacks $(15 \%)$. Based on the cancer site, the incidence of HPV-related cancers among whites was higher (>63\% and more) than among blacks, except for anal cancer, where blacks had a slightly higher incidence (54\% in females and 57\% in males) (Table 2).

Furthermore, stratifying by tribes, the incidence among natives, especially among Tabu (1\%) and Touareg (2\%), were considered consistently low, whereas the native Berbers were high (33\%) similarly to Arabs (37\%) and of European origin (27\%). In gender stratification within ethnicity; ethnic differences were for some types of HPV-related cancers in which whites (85\%) had a high incidence of pharyngeal cancer $(77 \%$ females, $96 \%$ males). Among women, whites had the highest incidence of ovary cancer $(83 \%)$ and vulvar cancer (85\%). Tribes of Tabu, Touareg, and Berbers had consistently lower rates (Table 2).

In a parallel study, a total of 300 respondents had completed the questionnaire, of whom only $0.125 \%$ were aware of and knew about the HPV vaccination (Table 3). Furthermore, the acceptability of HPV vaccination was explored, resulting in 63\% who were willing to be vaccinated, whereas the other $37 \%$ were a negative their attitude regarding the vaccine. Those unwilling to be vaccinated believed that they had no risk of developing HPV infection, genital warts, or even cervical cancer or other cancers. Other $17 \%$ were worried that there was no use of the HPV vaccine in Libya. Respondents concerned with the safety and the efficacy of HPV vaccination accounted for $20 \%$, participants who questioned the source of the vaccine and showed concern regarding the high price of the vaccine were $63 \%$. More than $83 \%$ of participants agreed on educating the community about HPV infection and vaccines.

\section{Discussion}

Our study provided an important source of baseline data for HPV-related cancers in Libya in the last decade 2011-2020. There were $58.1 \%$ infected HPV-related cancers of total 57,620 cancer cases in the National Cancer Registry, which predominantly (75.4\%) affect women. Through this report, it is advised to improve awareness of the HPV vaccine and to reduce the burden of HPV-related cancers and diseases. Currently, approval by the Libyan Ministry of Health and the Libyan government to adopt the HPV vaccine is awaiting. Vaccination against HPV may reduce the incidence of HPV-related cancers and precancerous lesions in Libya, therefore, 
Table 2 Incidence of HPV-related Cancers Sites by Ethnicities and Gender in Libya from 2011 to 2020

\begin{tabular}{|c|c|c|c|c|c|c|c|c|c|c|c|c|c|c|}
\hline \multirow{4}{*}{ Cancer Site } & \multicolumn{4}{|c|}{ Skin color } & \multicolumn{10}{|c|}{ Ethnicity } \\
\hline & \multicolumn{2}{|c|}{ Black } & \multicolumn{2}{|c|}{ White } & \multicolumn{6}{|c|}{ Native } & \multicolumn{2}{|c|}{$\begin{array}{l}\text { Asian } \\
\text { Origin } \\
\text { (Arabs) }\end{array}$} & \multicolumn{2}{|c|}{$\begin{array}{c}\text { European } \\
\text { Origin }\end{array}$} \\
\hline & \multirow{2}{*}{$\mathbf{n}$} & \multirow{2}{*}{$\%$} & \multirow{2}{*}{$\mathbf{n}$} & \multirow{2}{*}{$\%$} & \multicolumn{2}{|c|}{ Tabu } & \multicolumn{2}{|c|}{ Berber } & \multicolumn{2}{|c|}{ Touareg } & \multirow{2}{*}{$\mathbf{n}$} & \multirow{2}{*}{$\%$} & \multirow{2}{*}{$\mathbf{n}$} & \multirow{2}{*}{$\%$} \\
\hline & & & & & $\mathbf{n}$ & $\%$ & $\mathbf{n}$ & $\%$ & $\mathbf{n}$ & $\%$ & & & & \\
\hline $\begin{array}{l}\text { HPV-related } \\
\text { cancers in } \\
\text { female: }\end{array}$ & 1,773 & 15 & 9,869 & 85 & 49 & 1 & 1,452 & 33 & 105 & 2 & 1,648 & 37 & 1,200 & 27 \\
\hline Ovary & 1,110 & 17 & 5,356 & 83 & 745 & 27 & 347 & 12 & 201 & 7 & 725 & 26 & 780 & 28 \\
\hline Cervix & 1,463 & 37 & 2,532 & 63 & 965 & 20 & 844 & 18 & 796 & 16 & 1,140 & 24 & 1,046 & 22 \\
\hline Anus & 1,801 & 54 & 1,561 & 46 & 85 & 13 & 45 & 7 & 13 & 2 & 244 & 39 & 243 & 39 \\
\hline Vagina & 117 & 25 & 351 & 75 & 65 & 40 & 17 & 10 & 9 & 6 & 59 & 37 & 11 & 7 \\
\hline Vulva & 198 & 15 & 1,089 & 85 & 113 & 28 & 34 & 8 & 27 & 7 & 165 & 40 & 71 & 17 \\
\hline Oropharynx & 123 & 23 & 421 & 77 & 35 & 8 & 15 & 4 & 12 & 3 & 123 & 30 & 223 & 55 \\
\hline $\begin{array}{l}\text { HPV-related } \\
\text { cancers in } \\
\text { male: }\end{array}$ & 814 & 16 & 4,390 & 84 & 126 & 6 & 215 & 10 & 0 & 0 & 928 & 42 & 907 & 42 \\
\hline Penis & 109 & 11 & 880 & 89 & 89 & 15 & 2 & 0 & 2 & 0 & 287 & 46 & 245 & 39 \\
\hline Anus & 951 & 57 & 730 & 43 & 170 & 15 & 161 & 14 & 10 & 1 & 330 & 28 & 480 & 42 \\
\hline Oropharynx & 129 & 4 & 2,987 & 96 & 32 & 3 & 211 & 21 & 154 & 16 & 229 & 23 & 372 & 37 \\
\hline
\end{tabular}

Note: Color skin is divided into Black and White. Ethnicity is divided by Native (Tabu, Berbers, Touareg,); Asian origin (Arabs: Yemenite Gulf, Levant, and Iraq); European origin (Turks, Caucasians, Albanians, and Armenians).

initial responses to the HPV vaccination within the Libya public are favorable.

Not surprisingly, it sparked debate about data on HPV and related cancers in men and women, suggesting that HPV infection contributed to anal, penile, pharyngeal, and other cancers; given the specific link between HPV and penile, anal and pharyngeal cancer found in men who had sex with men. The incidence of cancer-related HPV infection is high among Libyan women. The rate of anal cancer is higher in men, about $36 \%$; while the pharyngeal or oropharynx cancer rate is about $50 \%$ higher. For all combinations of HPV and penile-related sites, the rate is in the $14 \%$ range (Table 1). The incidence of hypopharyngeal cancer among men is two times higher than that of women.

Interestingly, the increased incidence of men might be due to several factors, including smoking and alcohol use which are both responsible for hypopharyngeal cancer. ${ }^{16,17}$ Furthermore, the cancer rate might be high due to sexual behavior and unhealthy diets. However, the pattern of HPV-associated cancers seemed to affect men only. As for cervical and ovarian cancer in women, which have higher rates, sexual behavior and genetic factors might be the predominant risk factors. The results have shown that men are more susceptible to pharyngeal cancer for several reasons and factors, including HPV and smoking, alcoholic beverages, and drugs. Moreover, blacks have a high incidence of anal cancer (47\% females, $57 \%$ males) and Europeans (42\%), while Arabs (46\%), and Europeans (39\%) have a high incidence of penile cancer.

All HPV-related cancers have covered nearly all types of cervical cancer and some types of cancers of the vulva, vagina, penis, anus, and pharynx. As for the pharynx, HPV might infect the back of the throat, base of the tongue, and tonsils. Interestingly, the medical records noted that there were patients with two or more types of genital cancers such as ovarian and uterine cancer, or otherwise with another site such as colorectal and ovarian cancer at the same time. Moreover, there were those afflicted with two types such as uterine, renal cell carcinoma (RCC) and cancer of unknown primary (CUP); also, ovarian and CUP, NonHodgkin lymphoma (NHL) and cervix cancer; otherwise, vagina and cervix; bladder, ovary, cervix cancers; (ovarian, gastrointestinal cancer and CUP; CA-125 ovarian and uterine; Rectal cancer, colon cancer, ovary), and others. We did not find the explanation for these cases, 
Table 3 Knowledge and Awareness around HPV and HPV Vaccine

\begin{tabular}{|c|c|c|c|c|c|c|c|c|}
\hline \multirow{3}{*}{ Knowledge Statement } & \multicolumn{4}{|c|}{ Answer } & \multicolumn{4}{|c|}{ Gender } \\
\hline & \multicolumn{2}{|c|}{ Know } & \multicolumn{2}{|c|}{ Do not know } & \multicolumn{2}{|c|}{ Female } & \multicolumn{2}{|c|}{ Male } \\
\hline & $\mathbf{n}$ & $\%$ & $\mathbf{n}$ & $\%$ & $\mathbf{n}$ & $\%$ & $\mathrm{n}$ & $\%$ \\
\hline History of Papillomavirus (HPV) related lesions & - & - & 300 & 100 & - & & - & - \\
\hline HPV infection is widespread & - & - & - & - & 300 & 100 & - & - \\
\hline HPV can cause serious diseases & - & - & 300 & 100 & - & - & - & - \\
\hline HPV can infect both genders & 4 & 1 & 296 & 96 & 1 & - & 3 & - \\
\hline Most HPV infected people develop cancer & 3 & 1 & 297 & 97 & 1 & - & 2 & - \\
\hline HPV can lead to genital warts (GWs) & - & - & 300 & 100 & - & - & - & - \\
\hline GWs affect both genders & - & - & 300 & 100 & - & - & - & - \\
\hline HPV-related with penile cancer & - & - & 300 & 100 & - & - & - & - \\
\hline HPV-related with CC & - & - & 300 & 100 & - & - & - & - \\
\hline $\begin{array}{l}\text { HPV infection transmission through sexual } \\
\text { intercourse }\end{array}$ & - & - & 300 & 100 & - & - & - & - \\
\hline $\begin{array}{l}\text { Early sexual debut increases the risk of } \\
\text { contracting HPV }\end{array}$ & - & - & 300 & 100 & - & - & - & - \\
\hline $\begin{array}{l}\text { Using condoms reduces the risk of HPV } \\
\text { transmission }\end{array}$ & - & - & 300 & 100 & - & - & - & - \\
\hline $\begin{array}{l}\text { A high number of sexual partners increases the } \\
\text { risk of contracting HPV }\end{array}$ & - & - & 300 & 100 & - & - & - & - \\
\hline $\begin{array}{l}\text { HPV infection transmitted from mother to child } \\
\text { during pregnancy and delivery }\end{array}$ & 1 & 1 & 299 & 100 & 1 & - & - & - \\
\hline $\begin{array}{l}\text { HPV infection transmission from a carrier to his/ } \\
\text { her partner only if the carrier shows symptoms }\end{array}$ & - & - & 300 & 100 & - & - & - & - \\
\hline A person may be HPV-infected and is unaware & 5 & 2 & 295 & 97 & - & - & 3 & 1 \\
\hline There are no specific therapies for HPV infection & - & - & 300 & 100 & - & - & - & - \\
\hline Heard about HPV vaccine & 2 & 1 & 296 & 98 & - & - & 2 & 1 \\
\hline Anti-HPV vaccine is safe & 1 & 1 & 299 & 100 & - & - & 1 & - \\
\hline Both genders can be vaccinated against HPV & 2 & 1 & 298 & 99 & 1 & - & 1 & - \\
\hline $\begin{array}{l}\text { HPV vaccine is effective after starting sexual } \\
\text { activity }\end{array}$ & - & - & 300 & 100 & - & - & - & - \\
\hline $\begin{array}{l}\text { Anti-HPV vaccination must be mandatory for } \\
\text { boys and girls before the sexual debut and for at } \\
\text { risk subjects }\end{array}$ & - & - & 300 & 100 & - & - & - & - \\
\hline Ages recommended the vaccines between 9 to 12 & - & - & 300 & 100 & - & - & - & - \\
\hline $\begin{array}{l}\text { Anti-HPV vaccines are capable of preventing the } \\
\text { occurrence of CC and GWs }\end{array}$ & 3 & 1 & 297 & 97 & 1 & - & 2 & - \\
\hline Total \% & 0.125 & - & 99.875 & - & - & - & - & - \\
\hline
\end{tabular}

as it was unknown why cancer appeared in two or more genitals and other organs in the same patient. Perhaps, there was a link between several factors such as early marriage, sexual disorder, reproduction, frequent miscarriages, early sexual life, diet, race, and homosexuals with two or more sex partners. To hypothesize, this may occur due to an interaction between environmental and genetic factors, leading to abnormal gene expression and HPV infection. 
Thus, functional changes to oncogenes play a significant role in the occurrence and evolution of HPV-16 and HPV-18 rates associated with rates of estrogen receptor (ER), progesterone receptor (PR), Tumor protein P53, and KI67 infection.

Moreover, HPV also destroys the normal sex hormone function, which weakens the antiestrogenic effect of progesterone in the organs and increases the malignant transformation of cells. HPV may induce cell cycle activity of KI67 positive cells; as the expression level of KI67 increases, the numbers of copies of HPV also increase. There is no logical explanation for having multiple carcinomas in different organs of the same person.

Based on the cancer site, the incidence of HPV-related cancers among whites was higher ( $>63 \%$ and more) compared to blacks, except in anal cancer, of which blacks had a slightly higher incidence $54 \%$ in females and $57 \%$ in males). Oropharynx cancer was higher in white men $(96 \%)$ than in white women (77\%). Based on ethnicity, native Libyans such as Tabu, Touareg, and Berbers had different cancer sites.

The challenge of this study was the community's awareness of HPV-related cancers and vaccines against HPV. The knowledge and awareness of HPV and related cancer were inadequate among the population in Libya. Libyan-born Tabu and Berbers had the lowest HPV positivity in fewer HPV risk behaviors, including early age at first sexual intercourse, multiple sexual partnerships, and current smoking. The congruent genotypes and the biological factor might be responsible for HPV infection, and prevention of HPV depended on the awareness and promotion of vaccines against HPV and the number of doses allowed according to types of HPV vaccination. In high-risk HPVs, viruses that have a high possibility to develop cancer, include genotype HPV 16, 18, 31, 33, 35, 39, 45, 51, 52, 56, 58, and 59; of which two genotypes are the most prevalent, which are genotype HPV 16 and 18, causing the majority of HPV-linked cancers. ${ }^{14,15}$ There are vaccines for HPV available, which cover high-risk HPV genotype 16 and 18 (2-valent), and another one also covers lowrisk HPV genotype 6 and 11 (4-valent). Genital warts, predominantly caused by low-risk HPV genotype 6 and 11, are not carcinogenic. Recently, the 9-valent (Gardasil 9) vaccine is available consisting of 9 genotypes HPVs (6, $11,16,18,31,33,45,52$, and 58). ${ }^{18} \mathrm{~A}$ two-dose series of HPV vaccines for both genders should be given as early as nine years. ${ }^{19}$ In addition, a three-dose series may be given to those who start the vaccine series at age 15 or older, and to people with certain weakened immunity. Vaccination against HPV is also recommended up to 26 years for women and 21 years for men who have not received adequate vaccinations.

Thus, adolescents should be vaccinated before exposure to HPV infection or be sexually active. Interestingly, most women under the age of 30 can self-clear HPV infection on their own within a few months or years. The vaccine will not eliminate HPV infection. Besides, the vaccine does not protect against all types of HPV, therefore, even women who are already vaccinated, still need to have regular Pap and pelvic exams, as the vaccine's effectiveness is not known yet.

There is a lack of knowledge and awareness of HPV infection and vaccines, therefore, educational initiatives are essential. The importance of organized enlightenment for health care workers and the media, who are the most preferred sources of information, is imperative. Due to the low knowledge level, the media and health professional promotion need to raise awareness.

This study used secondary data, so it faced several limitations, among others; the data was not supported by the age of the respondents. A better database in age groups could further support cancer management as cancer-related HPV infection was significant among different age groups.

To conclude, HPV-related cancer has infected $60 \%$ of women and $52 \%$ of men. Ovarian and cervical cancers in women are the predominant cases, and the oropharynx and anal are more prevalent in men. Although HPV cancers represent a high percentage of the cancer burden among Libyans, knowledge and awareness on HPV and related cancers are lacking. Better education and provision of HPV vaccines for future generations may eliminate and reduce HPV-related cancers. Furthermore, due to low knowledge levels, media and the promotion of health professionals must raise community awareness.

\section{References}

1. Giuliano AR, Lu B, Nielson CM, Flores R, Papenfuss MR, Lee JH, et al. Age-specific prevalence, incidence, and duration of human papillomavirus infections in a cohort of 290 US men. J Infect Dis. 2008;198(6):827-35.

2. Korbag S, Korbag I. A new study biological role of HPV infection, oral contraceptive 
use, sex hormones and bisphenol $\mathrm{A}$ and increase rate cancer of cervical in Libya. J. Med Chem Sci. 2020;3(4):354-62.

3. Petrosky E, Bocchini Jr. JA., Hariri S, Chesson H, Curtis CR, Saraiya M, et al., Use of 9-valent human papillomavirus (HPV) vaccine: updated HPV vaccination recommendations of the advisory committee on immunization practices. MMWR Morb Mortal Wkly Rep. 2015; 64(11): 300-4.

4. Brianti P, De Flammineis E, Mercuri SR. Review of HPV-related diseases and cancers. New Microbiol. 2017;40(2):80-5.

5. Brewer NT, Fazekas KI. Predictors of HPV vaccine acceptability: a theory-informed, systematic review. Prev Med. 2007;45(23):107-14.

6. Stanley M. HPV vaccination in boys and men. Hum Vaccin Immunother. 2014;10(7):2109-11.

7. Bharadwaj M, Hussain S, Nasare V, Das BC. HPV \& HPV vaccination: issues in developing countries. Indian J Med Res. 2009;130(3):327-33.

8. St Laurent J, Luckett R, Feldman S. HPV vaccination and the effects on rates of HPV-related cancers. Curr Probl Cancer. 2018; 42(5):493-506.

9. Centers for Disease Control and Prevention (CDC). Recommendations on the use of quadrivalent human papillomavirus vaccine in males-advisory committee on immunization practices (ACIP), 2011. MMWR Morb Mortal Wkly Rep. 2011; 60(50):1705-8.

10. Parkin DM, Bray F. Chapter 2: the burden of HPV-related cancers. Vaccine. 2006; 24 Suppl 3:S3/11-25.

11. McBride KR, Singh S. Predictors of adults' knowledge and awareness of HPV, HPVassociated cancers, and the HPV vaccine: implications for health education. Health
Educ Behav. 2018;45(1):68-76.

12. Winer RL, Lee SK, Hughes JP, Adam DE, Kiviat NB, Koutsky LA. Genital human papillomavirus infection: incidence and risk factors in a cohort of female university students. Am J Epidemiol. 2003;157(3):218-26.

13. Moscicki AB, Schiffman M, Kjaer S, Villa LL. Chapter 5: Updating the natural history of HPV and anogenital cancer. Vaccine. 2006;24 Suppl 3:S3/42-51.

14. Wilkin T, Lee JY, Lensing SY,Stier EA, Goldstone SE, Berry JM, et al. Safety and immunogenicity of the quadrivalent human papillomavirus vaccine in HIV-1-infected men. J Infect Dis. 2010; 202(8):1246-53.

15. Chin-Hong PV, Palefsky JM. Natural history and clinical management of anal human papillomavirus disease in men and women infected with human immunodeficiency virus. Clin Infect Dis. 2002;35(9):1127-34.

16. Palefsky JM. Human papillomavirusrelated disease in men: not just a women's issue J Adolesc Health. 2010;46(4 Suppl):S12-9.

17. Wendland EM, Kops NL, Comerlato J, Horvath JDC, Bessel M, Sperb D, et al. STOP HPV study protocol: a nationwide casecontrol study of the association between oropharyngeal cancer and human papillomavirus (HPV) infection in Brazil. BMJ Open. 2020;10(1):e031602.

18. Signorelli C, Odone A, Ciorba V, Cella P, Audisio RA, Lombardi A, et al. Human papillomavirus 9-valent vaccine for cancer prevention: a systematic review of the available evidence. Epidemiol Infect. 2017;145(10):1962-82.

19. Stanley MA, Sudenga SL, Giuliano AR. Alternative dosage schedules with HPV virus-like particle vaccines. Expert Rev Vaccines. 2014;13(8):1027-38. 